P95 (continued)

Results: Preliminary findings suggest the RF domains of Restriction, Pressure to Eat, Encouragement, and Praise represent salient teacher behaviors frequently observed within ECE infant classrooms.

Conclusion: This RF observational coding scheme is specific for ECE settings. Further refinement and validation with larger data collections across multiple ECE settings will be conducted to assess provider feeding practices. Such evidence will create new opportunities to improve RF education, implementation, and practice.

Funding: US Department of Health and Human Services.

\section{P96 Evaluation of the Effect of an Online Dual Enrollment Nutrition Course for College and High School Students}

Tracy Noerper, PhD, LDN, RDN, tracy.noerper@lipscomb. edu, Lipscomb University, One University Park Dr, Nashville, TN 37204; Janet Colson, PhD, RDN, Middle Tennessee State University; Andrew Owusu, PhD, Middle Tennessee State University

Background: Dual enrollment involves simultaneous enrollment in two or more courses at distinctly different educational levels such as secondary and tertiary. Dual enrollment programs can facilitate the transition of high school students into post-secondary education, and may reduce attrition rates in allied health programs. Dual enrollment is a rapidly growing segment of post-secondary education, yet there is a paucity of data concerning the nature and effectiveness for such programs in online nutrition education.

Objective: This project implemented a fully online undergraduate dual-enrollment nutrition course for high school and college students. Extent of attainment of course content was ascertained for all groups.

Study Design, Settings, Participants: USDA grant dollars were obtained to facilitate a two-year dual enrollment collaboration between college (C) and two high schools (HS1 and HS2). Two sections of junior-level high school students in HS1 $(n=11)$ and HS2 $(n=20)$, and one section of $C(n=29)$ completed a one-semester online three credit hour nutrition course. Course content focused on normal nutrition, was delivered using an online platform, and was identical for all students groups.

Measurable Outcome/Analysis: Pretest and posttest data were collected based on a 30-item nutrition knowledge test. A paired sample $t$-test was performed as well as an analysis of covariance (ANCOVA) to compare group mean differences.

Results: Paired sample $t$-test results indicate the mean difference between pretest and posttest scores $(M=32.4$, $S D=20.8, N=54)$ to be significantly greater than zero, $t(53)=11.5, P<.001$, [two-tailed]. ANCOVA results indicate a significant difference between groups on posttest scores when controlling for pretest scores, $F(2,50)=5.8$, $P=.01$. Adjusted mean posttest score for HS1 was significantly different from mean posttest scores for HS2 and C.
Conclusion: The results indicate that delivery of the online introductory nutrition course in the dual-enrollment program was effective in significantly improving nutrition knowledge of both high school and college students.

Funding: NIFA.

\section{P97 High School Teens Conduct Research to Understand Why Students are Not Drinking Water}

Marisa Neelon, MS, RD, mqneelon@ucanr.edu, University of California Cooperative Extension-Contra Costa County, 2380 Bisso Ln, Ste B, Concord, CA 94520; Charles Go, $P h D$, University of California Cooperative ExtensionContra Costa County; Eli Figueroa, BA, University of California Cooperative Extension-Contra Costa County

Background: In Contra Costa County, only $26 \%$ of teens drank eight or more glasses of water the previous day while $62 \%$ drank two or more sodas. Substituting water for sugarsweetened beverages can help reduce weight gain and the risk of developing chronic diseases. Healthy hydration while at high school can be a challenge for teens when free, safe, and appealing water is not accessible throughout the school day.

Objective: To engage youth in conducting research to better understand a teen hydration issue and create solutions to encourage students to meet daily water recommendations.

Study Design, Settings, Participants: An environmental scan revealed eight water fountains throughout the school, most did not work properly and/or did not have sufficient water flow. We engaged a group of students using the Youth-Led Participatory Action Research (YPAR) framework. Teens developed survey questions and used the Qualtrics survey system, including the offline app. Surveys were collected from 320 students: a $57 \%$ response rate.

Measurable Outcome/Analysis: The survey assessed student beverage choices, habits, access to drinking water, and appeal of water. The resulting quantitative data were analyzed using Qualtrics descriptive statistics options.

Results: Teens discovered $97 \%$ of students were drinking water, but $60 \%$ were not drinking water provided at school. Instead, students brought water from home because of broken fountains and a perception that the school's water was not safe. Consequently, the average student daily water consumption was 4.92 cups, less than the 8-cup recommendation. Using the research-based information, the teens created infographics to share their findings schoolwide and presented to the school board to advocate for water refilling stations. Board members approved funds to install six stations.

Conclusion: The YPAR framework helped us better understand the high school hydration issue. Teens plan to continue with peer education and promote existing water fountains and upcoming stations - encouraging students to meet daily water recommendations.

Funding: SNAP-Ed. 